论 文

\title{
2009/2010 年冬季北极涛动异常及其影响分析
}

\author{
李琳 $^{(1) *}$ ，李崇银 ${ }^{(1)}$ ，宋洁 ${ }^{(2)}$ \\ (1) 解放军理工大学气象学院, 南京 211101 ; \\ (2) 中国科学院大气物理研究所, 北京 100029 \\ *E-mail: 1len1983@163.com
}

收稿日期: 2011-03-01; 接受日期: 2011-06-01

国家重点基础研究发展计划(编号: 2010CB950400)和国家自然科学基金(批准号: U0833602)资助

摘要 2009/2010 年冬季出现了持续的北极涛动(AO)负异常, 同时北半球的天气气候也发 生了大范围的异常, 两者的关系是大家极为关注的重要问题. 本文的分析表明 2009/2010 年 冬季北半球经历了两次显著的 AO 负异常过程, 2009 年 12 月和 2010 年 2 月 AO 指数分别达 到了同期历史的最低值. 2009 年 12 月的 AO 负异常过程又可以又分为两个阶段，第一个阶段 是由于前期行星波上传的增强导致平流层极涡减弱，随后平流层环流异常向下发展造成了对 流层的 AO 负异常; 第二个阶段是因为对流层低层高纬地区的温度正异常维持了第一个阶段 在对流层高纬地区的位势高度正异常, 使得 $\mathrm{AO}$ 负异常得以较长时间维持, 这两个阶段的接 连发生和共同作用使得对流层低层经历了一个较强的 AO 负异常过程. 而 2010 年 2 月的 AO 负异常过程则是由平流层爆发性增温所造成的平流层异常环流下传造成的. 通过对历史上 11 个 $\mathrm{AO}$ 负异常事件的统计分析, 可以认为 $\mathrm{AO}$ 负异常事件可能由平流层爆发性增温以及平流 层极区弱的环流异常下传造成, 也可能来源于对流层内部的动力过程. 进一步研究表明, 2009/2010 年冬季持续的极端 AO 负异常与该冬季北半球大范围的温度和降水异常有密切联 系, 关注 $\mathrm{AO}$ 异常及其影响是天气预报、气候预测的重要问题.

关键词

北极涛动 $(\mathrm{AO})$

平流层环流异常

行星波

极端天气气候

爆发性增温
北极涛动 $(\mathrm{AO})$ 是北半球热带外地区大气环流变 化的最主要模态, 表现为北半球高纬度和中纬度地 区海平面气压场(SLP) 反相的“跷跷板”式振荡现象 ${ }^{[1]}$. 其后的研究表明, 对应极区的正(负)气压异常, 在北 半球中纬度地区往往有沿纬圈的带状负 (正)气压异 常区, 因此也将 AO 称之为环状模(NAM), 而且北大 西洋涛动 $(\mathrm{NAO})$ 也被认为是 $\mathrm{AO}$ 在北大西洋区域的一 种表现 ${ }^{[2]}$. 而后 $\mathrm{Li}$ 和 $\mathrm{Wang}^{[3]}$, 李建平 ${ }^{[4]}$ 的研究避开使 用 EOF 分析方法, 对 AO/NAM 的本质进行了研究, 并给出了更为清晰的物理概念图. 一些研究还发现,
$\mathrm{AO}$ 并不只是存在于对流层低层, 冬季 $\mathrm{AO}$ 可以从近 地面一直向上延伸到平流层, 具有准正压结构 ${ }^{[5]}$. 而 且 Baldwin 和 Dun Kerton ${ }^{[6]}$ 发现有一部分 AO 异常过 程首先发生在平流层上层, 然后向下传播, 经过大约 3 个星期到达地面. AO 的这一特点可能有助于提高 对流层天气延伸预报技巧 ${ }^{[7]}$. 此后一系列的研究都关 注于冬季平流层和对流层的耦合对于对流层 $\mathrm{AO}$ 的 预报意义以及对天气气候的重要影响 ${ }^{[8 \sim 12]}$. 但也有研 究指出, 欧亚大陆前期的雪盖异常可能是冬季 AO 模 态异常的重要原因, 并认为对流层的异常信号可能

英文引用格式: Li L, Li C Y, Song J. Arctic Oscillation anomaly in winter 2009/2010 and its impacts on weather and climate. Sci China Earth Sci, 2011, doi: 10.1007/s11430-011-4329-4 
更早于平流层出现 ${ }^{[13,14]}$.

已有的研究表明, 东亚冬季气候异常在年际尺 度上和 $\mathrm{AO}$ 之间存在一定的联系, $\mathrm{AO}$ 的异常对于我 国的天气气候有着重要的影响. Gong 等 ${ }^{[15]}$ 和龚道溢 等 ${ }^{[16]}$ 分析研究了北极涛动对我国及东亚气候的影响, 结果表明当 $\mathrm{AO}$ 指数偏强时, 我国大部分地区冬季气 温偏高, 同时降水也偏多; 而且, 当北极涛动偏强一 个标准差时, 整个中国长江中、下游地区到日本南部 一带的夏季降水会减少 3\% 9\%左右, 中国华北到俄 罗斯远东地区则偏多 3\% 6\%左右. 陈文和康丽华 ${ }^{[17]}$ 的研究认为 $\mathrm{AO}$ 的变化通过改变准定常行星波活动 影响西伯利亚高压, 进而影响东亚冬季风的强弱; Ren 和 $\mathrm{Cai}^{[18]}$ 研究了与北半球环状模相联系的温度变 化特征. 杨辉和李崇银 ${ }^{[19]}$ 的研究表明, 在冬季 AO 位 于不同位相时, 西风带和副热带的环流有很大的差 别, 当 AO 为显著正位相时, 东亚季风偏弱, 我国东 部、东北、新疆和内蒙古地区温度偏高. 李崇银等 ${ }^{[20]}$ 指出, 三月份的 $\mathrm{AO}$ 还会通过影响东亚地区夏季对流 层大气的冷暖状况和环流, 在长江中下游地区导致 异常垂直运动和辐散辐合形势, 从而影响夏季的梅 雨降水.

2009/2010 年冬季, AO 极端的负异常相伴随北半 球许多地区遭遇了历史罕见的低温和暴雪侵袭, 造 成了巨大的人员和经济损失. 例如我国东北大部及 内蒙古东部、新疆北部气温较常年偏低 $1 \sim 2^{\circ} \mathrm{C}$, 局部 偏低 $2 \sim 4{ }^{\circ} \mathrm{C}$; 东北大部、西北西部、东南沿海大部及 内蒙古西部和东北部等地降水偏多 3 成至 1 倍, 其中 东北北部及新疆北部、甘肃西北部、内蒙古西部等地 偏多 1 倍以上. 从图 1 可以清楚看到中国西北、东北 和华北北部都出现了明显的降水正异常, 不少地区 的降水量超过常年的 1 2 倍以上. 同时, 欧亚大陆中 高纬度大范围地区、北美洲中南部等地气温较常年同 期偏低 $1 \sim 3{ }^{\circ} \mathrm{C}$, 其中, 俄罗斯中北部、欧洲东北部偏 低 $3 \sim 6^{\circ} \mathrm{C}$; 而北美洲中南部、欧洲南部、亚洲中部和 东部等地的降水较常年同期偏多 3 成至 1 倍, 局部地 区偏多 1 倍以上.

2009/2010 年冬季北半球天气气候的大范围异常 被认为和这个冬季 $\mathrm{AO}$ 的显著负异常之间存在紧密 的联系. 因此, 本文详细分析了 2009/2010年冬季 AO 的异常形势, 并探讨了其形成的可能原因, 同时本文 也进一步研究了该冬季 $\mathrm{AO}$ 异常对北半球大气环流 和气候异常的影响. 进而深入认识 AO 异常的演变过

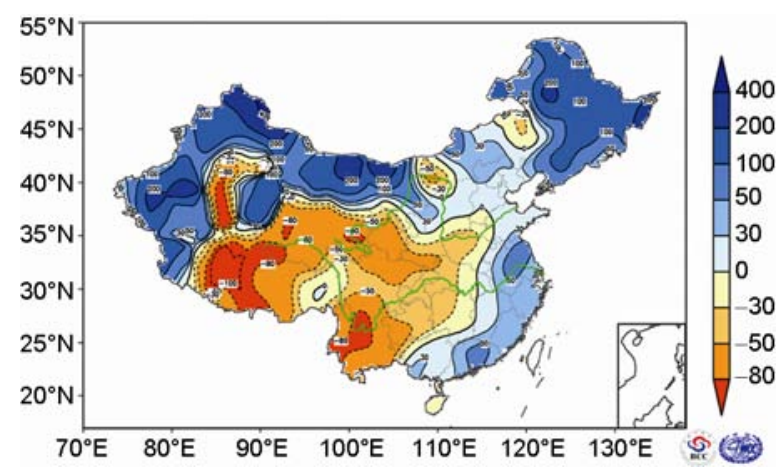

图 $12009 / 2010$ 年冬季中国降水量距平百分率 $(\%)$ 的分布 形势

国家气候中心提供

程、可能影响途径, 为 $\mathrm{AO}$ 异常事件的发生及其影响 的预测提供一定科学依据.

\section{1 资料和方法}

本文所采用的资料为 NCEP/NCAR 提供的逐日 和逐月再分析资料，时间跨度为 1948 年 1 月 1 日到 2010 年 2 月 28 日, 水平分辨率为 $2.5^{\circ} \times 2.5^{\circ}$, 垂直 17 层. 本文所定义的逐日(逐月)异常为每一格点上的原 始资料去除该格点逐日(逐月)多年气候平均值. 另外, 文中使用的逐月和逐日 AO 指数来源于美国气候预 测中心(CPC) (http://www.cpc.noaa.Gov/products/precip/ CWlink/daily_ao_index/ao_index.html). 降水资料来 自于国家气候中心中国 160 站月平均降水资料(http:// ncc.cma.gov.cn/cn/).

本文在研究行星波的上传特征时参考了 Chen 等 ${ }^{[21]}$ 使用 EP 通量诊断行星波活动的方法, 即定义:

$$
\begin{gathered}
F=\left(-\rho a \cos \varphi \overline{u^{\prime} v^{\prime}}, \rho a \cos \varphi \frac{R f}{H N^{2}} \overline{v^{\prime} T^{\prime}}\right), \\
D_{F}=\frac{\nabla \cdot \vec{F}}{\rho a \cos \varphi},
\end{gathered}
$$

其中, $F$ 为 $\mathrm{EP}$ 通量, $D_{F}$ 为 $\mathrm{EP}$ 通量散度, $\rho$ 是空气密度, $a$ 是地球半径, $\varphi$ 是纬度, $R$ 是空气常数, $f$ 是地转参数, $H$ 是大气标高, $N$ 为浮力频率, $u^{\prime}, v^{\prime}$ 和 $T^{\prime}$ 为准定常行星 波引起的风场和温度场的对应扰动量, 取纬向 1 3 波 表示行星波.

为了研究在负 $\mathrm{AO}$ 事件中平流层对对流层的影 响, 本文参考了 Baldwin 和 Thompson ${ }^{[22]}$ 的方法, 利 用 $\mathrm{AO}$ 指数随时间和高度的变化来表现平流层异常 
信号的下传过程.

\section{$22009 / 2010$ 年冬季 AO 异常特征分析}

我们在这一节将分析 2009/2010 年冬季 AO 的异 常特征. 首先我们给出 1950 2009 年 12 月和 1951 2010 年 2 月的月平均北极涛动指数的时间序列 (图 2(a)), 可以看到北极涛动具有很明显的年际变化 特征, 但其数值基本上在 \pm 3 之内. 然而 2009 年 12 月 和 2010 年 2 月的北极涛动指数却分别达到 -3.41 和 -4.27 , 是近 60 年来同月北极涛动指数的最低值, 表 明 2009/2010 年冬季的 AO 出现了极其严重的负异常. 为了更清楚地表现 2009/2010 年冬季 AO 指数的变化 特征, 我们给出了 2009 年 10 月 1 日到 2010 年 4 月 30 日逐日北极涛动指数的时间序列(图 2(b)). 逐日的 AO 指数表明 2009/2010 年冬季 AO 指数存在两个明 显的负异常事件. 第一个负异常事件从 12 月初开始, $\mathrm{AO}$ 指数逐渐由正值转为负值, 在 12 月 23 日达到最 小值(-5.557), 其后 AO 负位相强度虽略有减小, 但 随即在 1 月初其负异常强度又加大, 并于 1 月 4 日出 现第二个最小值(-5.403), 随后该负异常事件逐渐衰 减, 并于 1 月中旬结束第一个负异常事件. 这次负异 常事件持续时间长达 48 天. 第二个负异常事件从 1 月中旬开始, 几乎经历了一个与前一个异常事件相
类似的过程, 并在三月上旬结束, 最小值达到了 -5.205 , 持续时间为 47 天. 逐日 $\mathrm{AO}$ 指数的时间序列 表明, 2009/2010 冬季的 AO 几乎持续处于负异常状态, 这必然对北半球的大气环流和天气气候将产生重要 影响.

在位势高度场上, $\mathrm{AO}$ 反映的是高纬度与中纬度 之间的反相变化特征. 图 3 给出的是 2009 年 12 月和 2010 年 2 月 $1000 \mathrm{hPa}$ 位势高度距平的分布, 从图上 可以看到, 2009 年 12 月和 2010 年 2 月的 $1000 \mathrm{hPa}$ 位势高度距平场具有相同的特征, 即极地高纬地区 为很强的正距平, 而中纬度的北大西洋和北太平洋 各有一个较强的带状负距平中心, 这种距平分布清 晰地呈现出北极涛动负异常的模态特征. 通过比较 分析图 3 中正负距平值的大小及范围可以看出, 2010 年 2 月的 $\mathrm{AO}$ 异常更要强于 2009 年 12 月的 $\mathrm{AO}$ 异常, 这与前面月平均北极涛动指数异常的分析相一致.

前面已指出, 已有的研究表明在垂直方向上, $\mathrm{AO}$ 是一个深厚的系统. 平流层也存在清楚的极区和 中纬度地区位势高度呈反相变化的 $\mathrm{AO}$ 特征, 并且平 流层的 $\mathrm{AO}$ (也可视为平流层极浴)异常可以下传到对 流层并对对流层的天气气候产生一定的影响. 这里 我们对 2009/2010 年冬季 AO 的垂直结构特征及演变 进行分析, 图 4 给出了 2009 年 10 月到 2010 年 5 月 逐日 AO 指数的时间-高度剖面. 从 2009 年 12 月开始
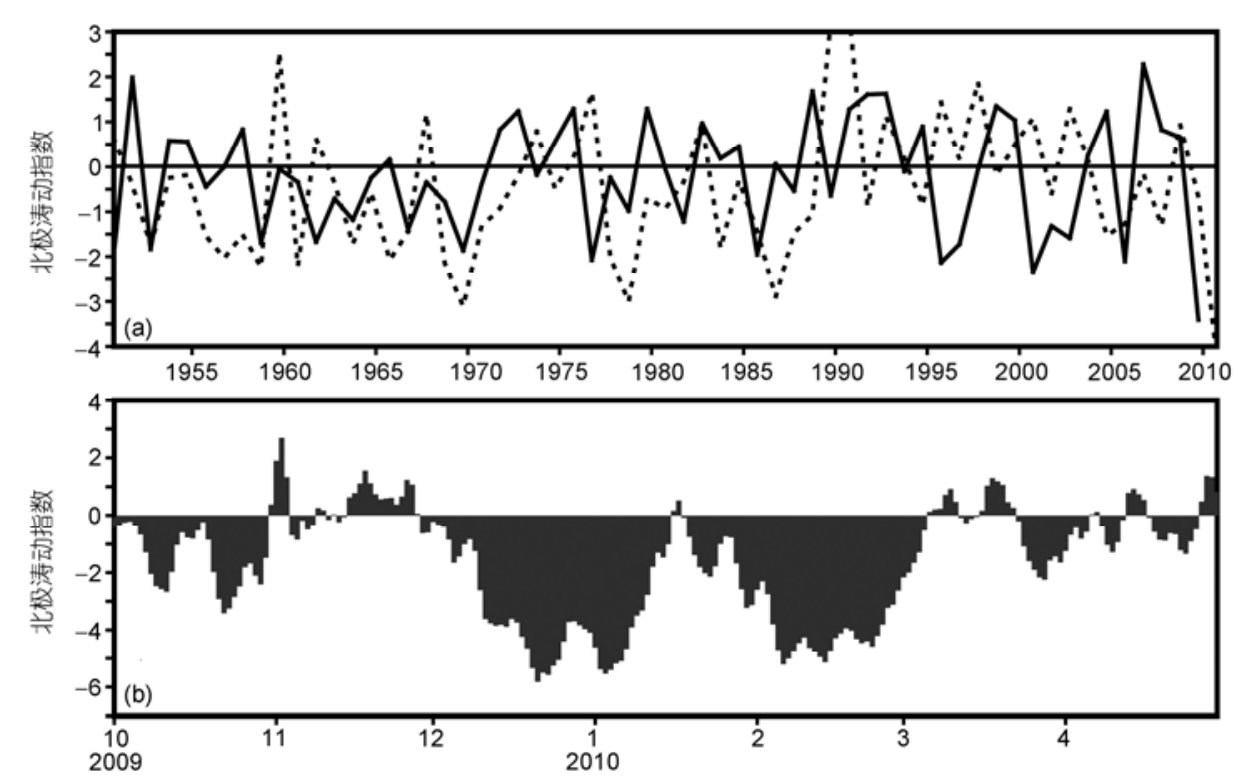

图 $21000 \mathrm{hPa}$ 上 12 月和 2 月北极涛动指数序列(a)和 $1000 \mathrm{hPa}$ 上逐日北极涛动指数序列(b)

(a) 实线表示 1950 2009 年 12 月, 虚线表示 1951 2010 年 2 月; (b) 时间范围为 2009 年 10 月 1 日至 2010 年 4 月 30 日 
到 2010 年 3 月平流层到对流层都经历了两次 $\mathrm{AO}$ 的 负异常过程, 具体的时间与前面分析的逐日 $\mathrm{AO}$ 指数 的变化相一致. 而且从图 4 还可以清楚看到, 2009/2010 年冬季的这两次 AO 负异常过程与平流层 AO 信号的下传有一定的关系, 尽管这两次异常过程 还有一些明显的不同特征. 第一次异常过程从 2009 年 12 月中上旬开始, 到 1 月上旬结束; 从指数的变化 来看, 第一次的异常过程又分为两个阶段：第一个阶 段是 12 月中上旬, $\mathrm{AO}$ 指数的最小值位于对流层的 500 200 hPa 之间, 并且 AO 负指数一直扩展到平流 层高层; 第二个阶段是 12 月中下旬到 2010 年 1 月初, $\mathrm{AO}$ 指数最小值位于对流层低层, 而其上的平流层为 正的 $\mathrm{AO}$ 指数, 对流层与平流层 $\mathrm{AO}$ 呈反相特征. 这 两个阶段的特征与前面分析逐日 AO 指数所指出的 12 月 $\mathrm{AO}$ 指数存在两个峰值有很好的对应. 第二次异
常过程从 1 月中下旬开始, 到 3 月初结束, 负 $\mathrm{AO}$ 指 数的最大值主要位于平流层, 但 2 月底在对流层低层 也出现了极值中心, 这次 $\mathrm{AO}$ 负事件过程中, 非常明 显平流层的 $\mathrm{AO}$ 指数的变化先于对流层. 需要说明的 是, 图 2(b)给出的是 $1000 \mathrm{hPa}$ 逐日北极涛动指数, 来 源于美国气候预测中心 (CPC), 是通过将逐日的资料 投影到月平均位势高度异常场 $\mathrm{EOF}$ 第一模态上得到 的. 图 4 中计算的 $\mathrm{AO}$ 指数是根据 Baldwin 和 Thompson ${ }^{[22]}$ 提出 Zonal-mean EOFs 方法得出的. 由 于方法的不同, 造成了两种指数的一些差异, 但基本 形势是一致的.

以上的分析表明, 2009/2010年冬季非常强的 AO 负异常存在两个明显的独立过程, 且这两个过程各 自表现出不同的特征. 下面我们将具体分析这两个 过程，进一步揭示这两次过程发生的原因.
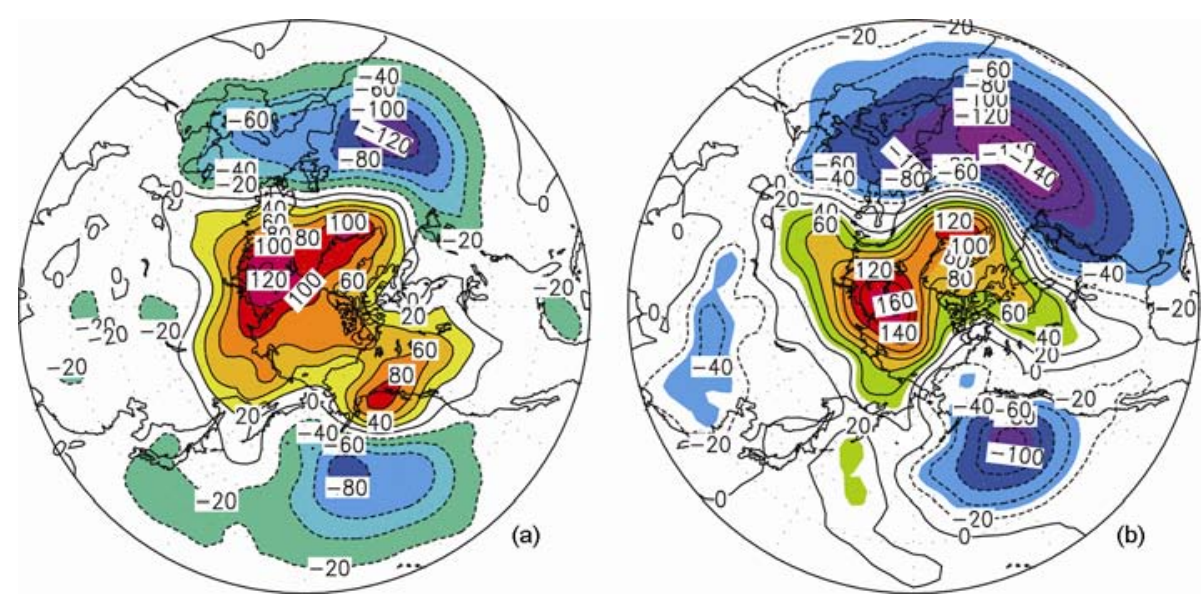

图 32009 年 12 月 (a)和 2010 年 2 月(b)的 $1000 \mathrm{hPa}$ 位势高度距平分布

阴影部分表示位势高度低于 $-20 \mathrm{gmp}$ 和高于 $20 \mathrm{gpm}$ 的区域, 位势高度的单位为 $\mathrm{gpm}$

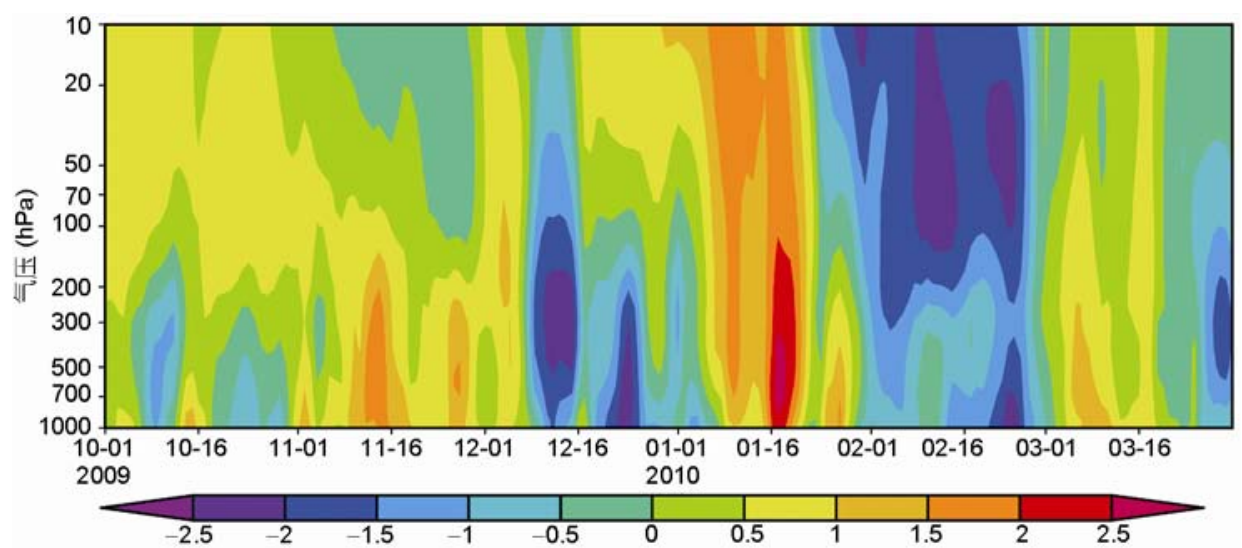

图 42009 年 10 月到 2010 年 4 月逐日 AO 指数的时间-高度剖面 


\section{$32009 / 2010$ 年冬季 AO 异常成因分析}

上面通过对 $\mathrm{AO}$ 指数随时间和高度变化的分析, 我们认为 2009 年 12 月到 2010 年 1 月初的 AO 负异 常事件有两个阶段. 第一个阶段在 12 月中上旬, 表 现为对流层和平流层的一致变化; 第二个阶段在 12 月中下旬到 1 月上旬, 表现为对流层和平流层 $\mathrm{AO}$ 的 反相变化, 并且最大负 $\mathrm{AO}$ 指数位于对流层低层. $\mathrm{AO}$ 的上述演变特征在 2009 年 12 月到 2010 年 2 月逐日 $60^{\circ} \mathrm{N}$ 以北的纬向平均位势高度距平和纬向风距平剖 面图上也有清楚的表现(图 5). 从图 5 可以看到, 位势
高度和纬向风的异常在 12 月中上旬在对流层和平流 层表现为一致的正异常或负异常; 极区高纬度的位 势高度正异常和纬向风负异常表明极涡发生了异常 减弱, 与之对应为 $\mathrm{AO}$ 的负异常. 其后, 平流层中上 层开始出现位势高度负异常和纬向风正异常，但从 对流层低层到平流层低层仍然都保持了位势高度正 异常和纬度向风负异常, 呈现出对流层与平流层反 相变化的情况; 同时, 还可以看到位势高度负异常和 温度负异常有清楚的由平流层向对流层传播的特征.

图 6 给出的是 2009 年 12 月第 2 侯到 2010 年 1 月第 1 侯纬向平均位势高度异常的纬度-高度剖面,
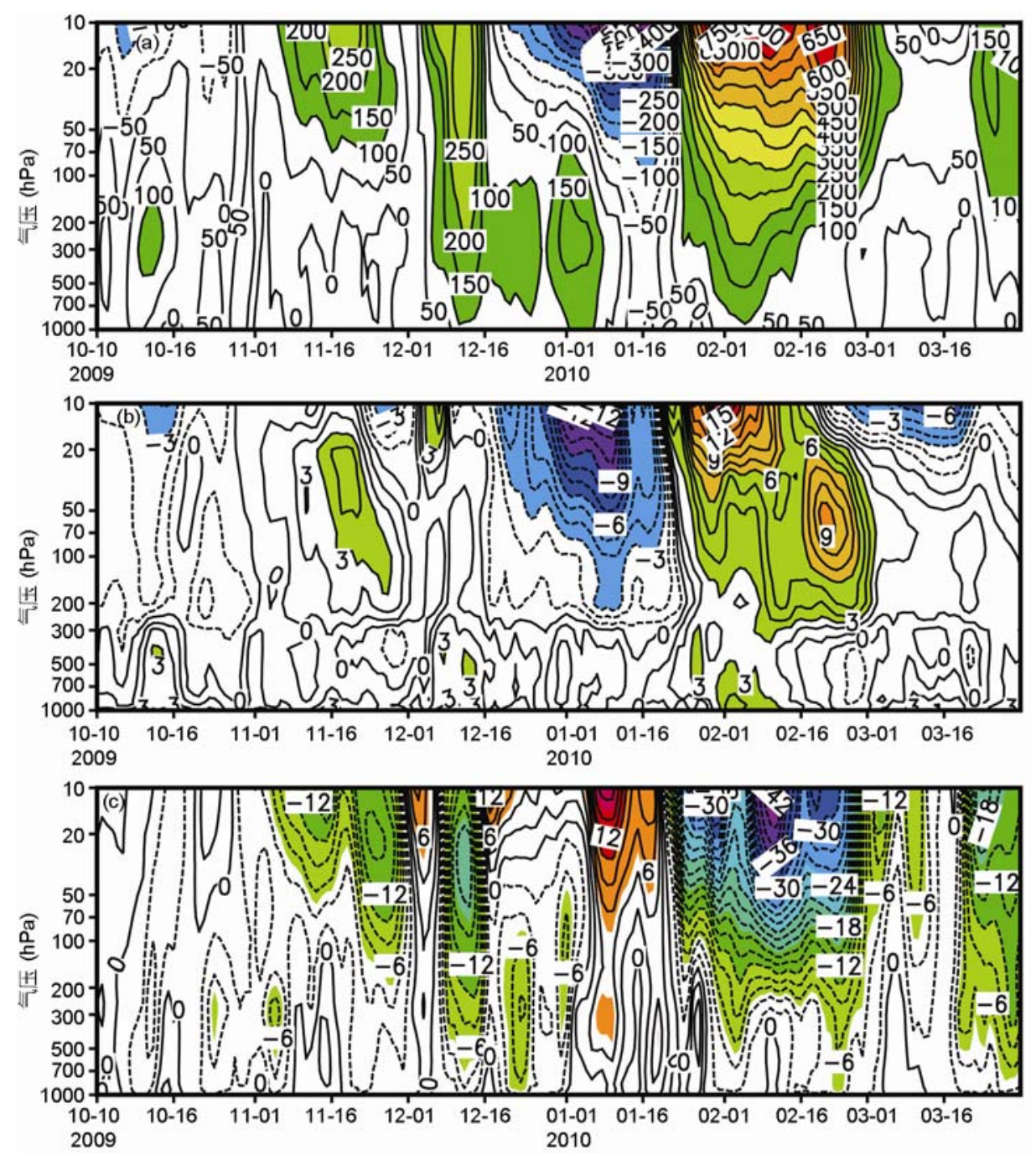

图 52009 年 12 月到 2010 年 3 月逐日的 $60^{\circ} \mathrm{N}$ 以北纬向平均位势高度距平 $(a) 、$ 温度距平 $(b)$ 和纬向风距平 (c)的时间-高度剖面

图中阴影表示各个量的大值区域. 位势高度的单位为 $\mathrm{gpm}$, 温度的单位为 $\mathrm{K}$, 纬向风的单位为 $\mathrm{m} \mathrm{s}^{-1}$ 

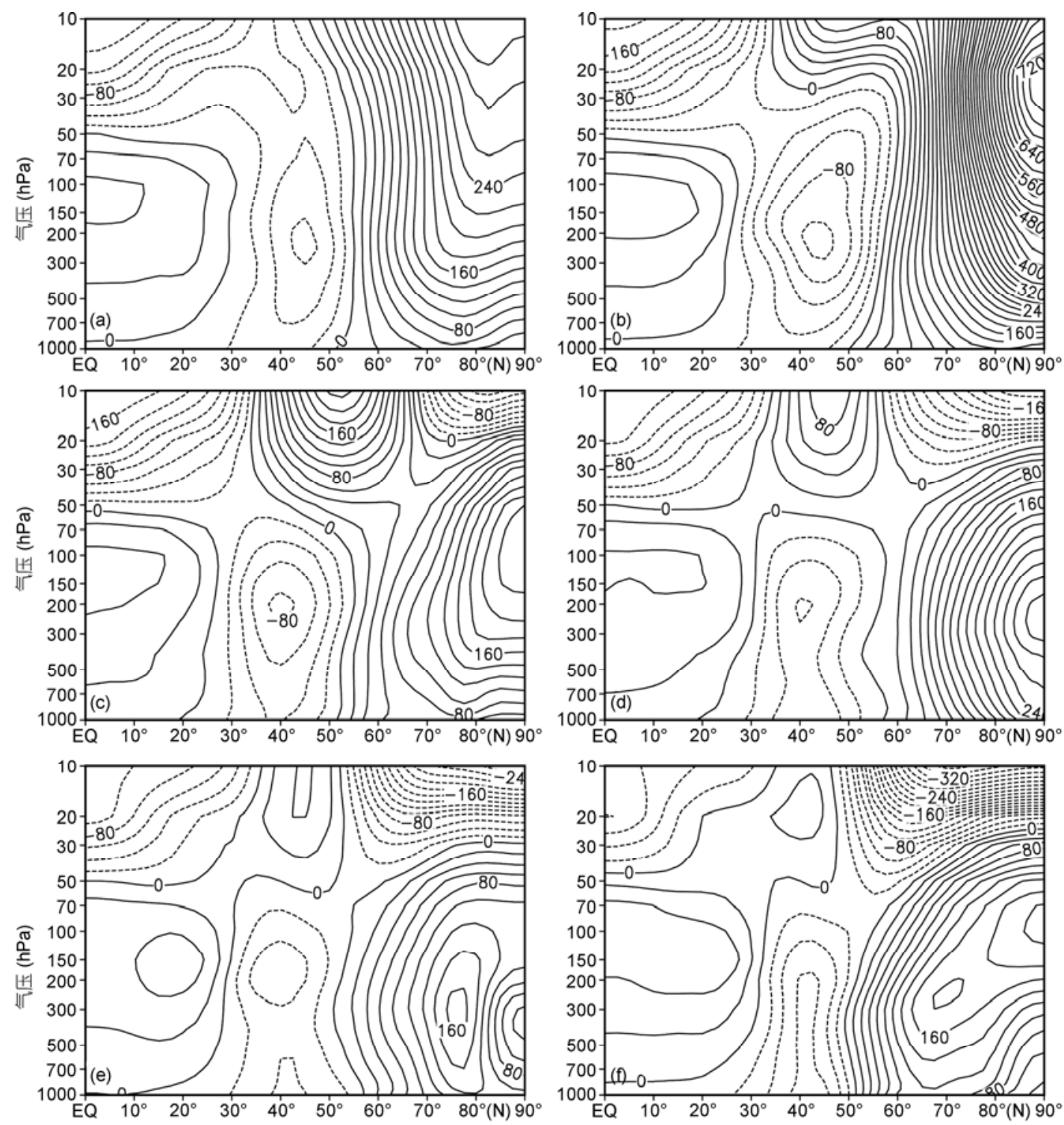

图 62009 年 12 月第二侯到 2010 年 1 月第一侯的纬向平均位势高度距平的纬度-高度剖面 图中等值线间隔为 $20 \mathrm{gpm}$. 位势高度单位为 gpm. (a) (f)分别为 2009 年 12 月第二侯到 2010 年 1 月第一侯

从图中可以看到在 12 月第 2 侯(图 6(a)) 北半球高纬度 地区从对流层到平流层有一致的位势高度正距平, 而中纬度为位势高度的负距平, 这种高纬度正距平 和中纬度负距平也就形成了 $\mathrm{AO}$ 的负异常型振荡. 在 12 月第 3 侯(图 6(b)) 平流层高层中纬度出现了位势高 度的正距平，12 月第 4 侯(图 6(c))平流层高层在高纬 度出现了位势高度的负距平, 形成了与低层相反的 AO 异常型. 我们还可以注意到中纬度的位势高度负 距平中心出现在对流层高层到平流层低层, 因而在
那里所形成的 $\mathrm{AO}$ 负异常最强, 这与前面分析的 $\mathrm{AO}$ 负指数最大值出现在对流层高层相一致. 虽然从 12 月第 4 侯开始, 平流层高层主要为位势高度的负距平, 但是位势高度负距平并没有快速向下发展，到 1 月初 位势高度负异常才到达对流层低层. 12 月中下旬对流 层到平流层低层在高纬度地区的位势高度正距平似 乎阻碍了高层位势高度负距平的向下发展, 并且与 中纬度的位势高度负距平共同形成了稳定的 AO 负 异常型特征, 并控制了整个对流层到平流层低层. 
图 7 给出的是 2009 年 12 月第 2 侯到 2010 年 1 月第 1 侯纬向平均温度距平的高度-纬度剖面, 由图 可以看到, 整个 12 月和 1 月上旬在对流层高纬度地 区都是较强的温度正距平, 其距平中心位于 1000 $\mathrm{hPa}$ 的高纬度地区. 我们还可以看到, 12 月第 2 侯平 流层高层在高纬度地区就已经出现了负的温度距平, 这个负的温度距平随时间一直在向下发展, 但由于 在对流层低层高纬度地区有正的温度距平存在, 源 于平流层的温度负距平没有能发展到达对流层低层.
可以认为, 正是由于对流层高纬度地区低层有正的 温度距平中心存在，使得高纬度的对流层维持了正 的位势高度距平，它与中纬度的位势高度负距平就 形成了稳定的 AO 负异常型特征，从而造成了 2009 年 12 月 $\mathrm{AO}$ 负异常型的第二个过程.

前面的分析指出 2009 年 12 月第 2 侯开始对流层 低层高纬度地区出现了持续时间较长的正温度异常, 这个正温度异常的存在维持了 2009 年 12 月 AO 负异 常的第一个过程，从而造成了 2009 年 12 月 AO 负异
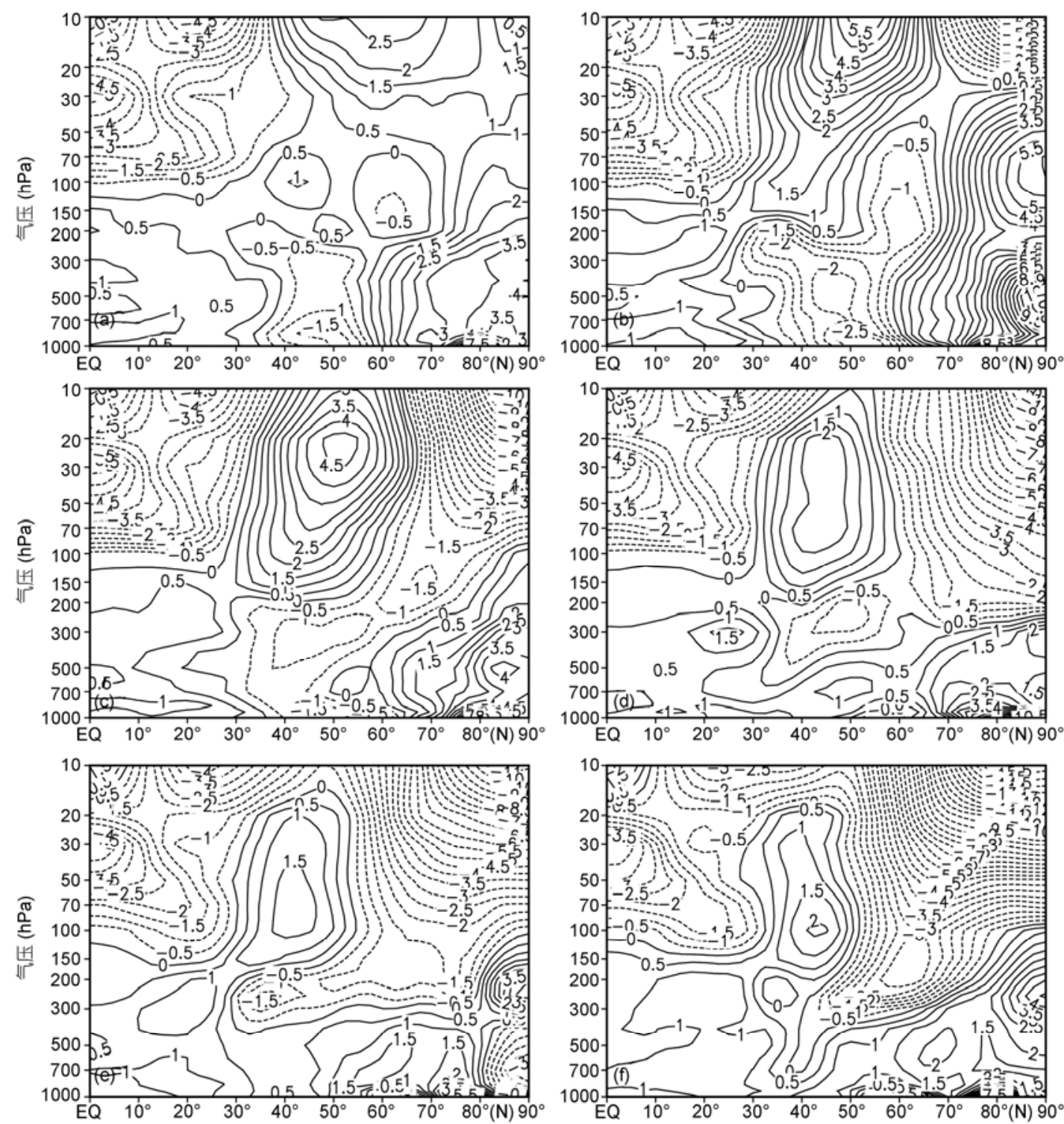

图 72009 年 12 月第二侯到 2010 年 1 月第一侯纬向平均温度距平的高度-纬度剖面

图中等值线间隔为 $0.5 \mathrm{~K}$, 温度的单位为 K. (a) (f) 分别为 2009 年 12 月第二侯到 2010 年 1 月第一侯 
常的第二个过程. 为了说明这个正温度异常形成的 原因，我们进一步分析了 2009 年 12 月第 2 侯到 2010 年 1 月第 1 侯平均的 $500 \mathrm{hPa}$ 位势高度场, 发现在 2009 年 12 月第 2 侯到 2010 年 1 月第 1 侯这段时间 内, 北大西洋持续存在一个明显的阻塞高压(图略). 通过分析逐日资料, 我们发现这个大西洋阻塞高压 维持了近 20 天. 在垂直方向上, 阻塞高压的结构一 直延伸到对流层高层的 $200 \mathrm{hPa}$ 左右. 由于阻塞高压 可以引起大尺度气团质量和热量的强烈经向交换, 我们认为大西洋阻塞高压的长时间维持可能是 2009 年 12 月第 2 侯到 2010 年 1 月第 1 侯对流层低层高纬 度地区出现正温度异常的重要原因.

已有的研究认为冬季准定常行星波(主要是由大 地形的动力强迫和海陆分布产生的热力强迫所激发) 可以在西风气流中上传到平流层 ${ }^{[23]}$, 并通过波流相
互作用对平流层环流产生一定的影响. 图 8 给出了 $60^{\circ} \mathrm{N}$ 以北 $200 \sim 10 \mathrm{hPa}$ 平均的纬向 1 3 波、1 波、2 波 EP 通量垂直分量时间序列的标准化, 用以表示上 传到平流层的行星波的变化. 从 1 3 波的情况来看, 上传到平流层的行星波存在一个月时间尺度的振荡 现象，分别在 11 月到 12 月上旬和 1 月中旬到 2 月上 旬存在两个峰值，表明这两段时间有较强的行星波 上传到平流层. 另外, 分别从 1 波和 2 波的情况来看, 只有 1 波的变化与 $1 \sim 3$ 波一致，说明这段时间 1 波起 到了主要作用. 上传行星波破碎后所释放的能量, 将 导致平流层西风气流减速和平流层增温, 当行星波 足够强的时候，西风气流可以从正常情况的西风急 流转换为东风，同时极区温度剧烈增加，引起平流层 的爆发性增温 ${ }^{[24]}$. 我们从图 8 上看到在 11 月到 12 月 上旬有较强的行星波的上传, 同前面图 5(a)中 12 月
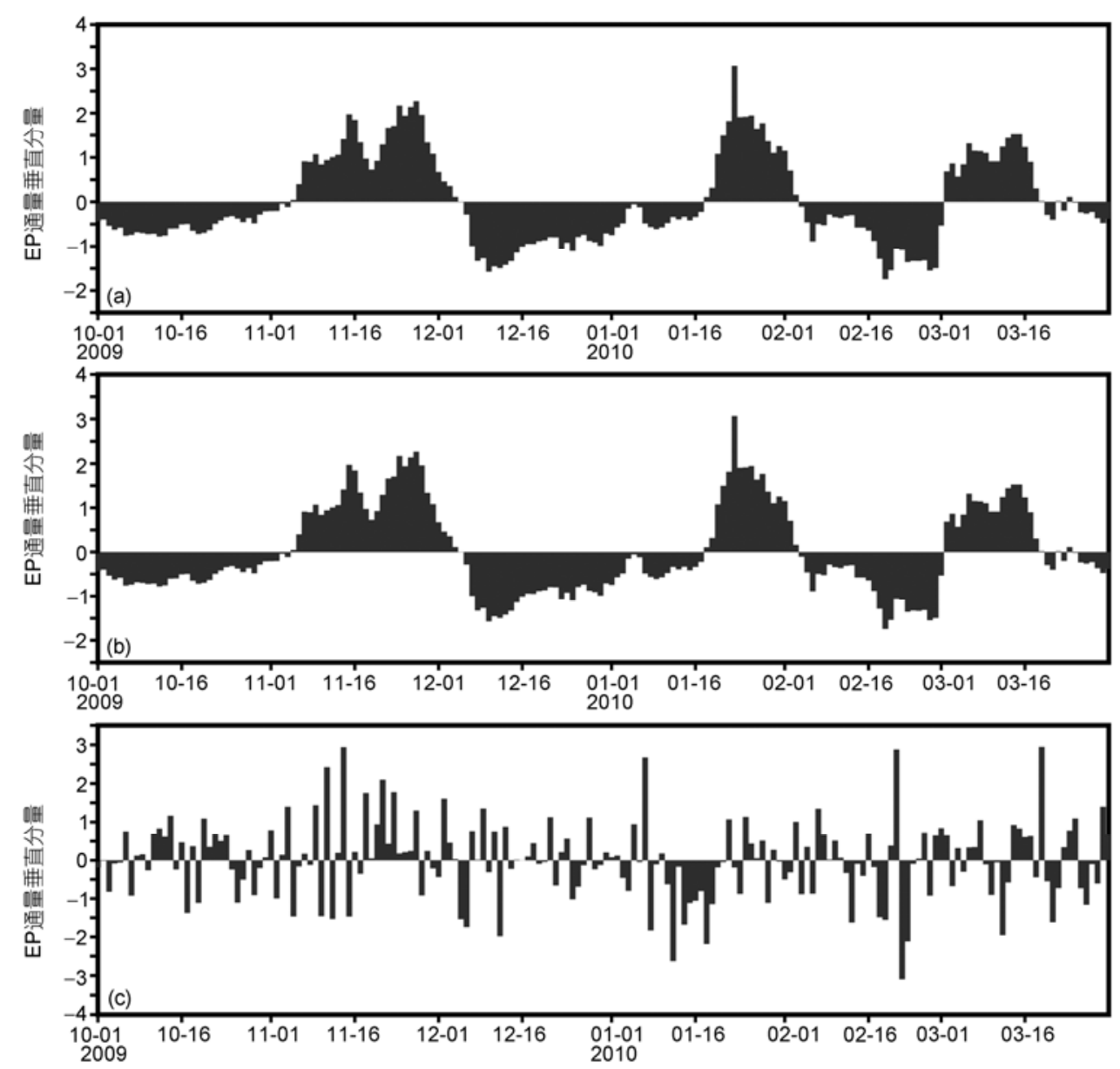

图 8 标准化 $60^{\circ} \mathrm{N}$ 以北 200 10 hPa 平均纬向 1 3 波(a)、1 波(b)、2 波(c) EP 通量垂直分量的时间变化 $E P$ 通量的单位为 $\mathrm{kg} \mathrm{s}^{-2}$ 
上旬有一个从平流层向对流层发展的正位势高度异 常相联系可以认为, 那次行星波上传的增强造成了 极浴减弱, 正位势高度异常的向下发展使得 12 月上 旬形成了高纬度地区从对流层到平流层都出现正位 势高度异常, 并且与中纬度的负位势高度异常构成 了从对流层到平流层的负 $\mathrm{AO}$ 型特征. 但这里需要指 出的是 11 月到 12 月上旬行星波上传的增强并没有造 成爆发性增温事件的发生, 只是导致了在极浴较弱 的平流层极区的增温, 这从图 9 中给出的温度差曲线 可以清楚看到. 在较强的行星波上传之后, 12 月中旬 开始行星波上传较弱, 这主要是由于从对流层到平 流层的西风气流的减弱, 而行星波上传减弱又使得 平流层的环流在辐射平衡的作用下从弱的极浴形势 开始恢复, 这使得从 12 月第 4 侯开始平流层高层在 高纬度地区出现了负位势高度异常(图 5(a)).

前面讨论了第一个负 $\mathrm{AO}$ 事件发生的过程, 相对 于第一个过程而言, 第二个负 $\mathrm{AO}$ 事件发生的过程比 较简单. 图 9 给出了 2009 年 10 月到 2010 年 3 月 20 $\mathrm{hPa}$ 极涡内外纬向平均温度和位势高度差值的时间演 变特征, 可以看到在 1 月下旬极浴内外的温度梯度和 位势高度梯度发生了明显的反转, 这与平流层强爆 发性增温的特征是一致的. 另外, 从图 4 我们也可以 看到从 1 月下旬开始从平流层到对流层有较强的正 位势高度异常、正温度异常和负纬向风异常. 而且在 纬向平均纬向风场上, 1 月下旬平流层出现了东风并 且持续了 1 个月以上, 说明强懪发性增温后极浴发生 了崩溃. 从行星波的变化来看, 1 月上旬之前有较强 的行星波上传到平流层, 而根据 Matsuno ${ }^{[25]}$ 的理论强 行星波上传可以造成爆发性增温的发生. 强爆发性 增温发生后, 平流层高层极区环流发生重大变化, 形
成了较强的平流层极涡负异常(也可视为平流层 $\mathrm{AO}$ 负异常), 平流层 $\mathrm{AO}$ 负异常向下传播并对对流层产 生影响, 造成了第二个 AO 负异常过程. 这些都与强 爆发性增温时 $\mathrm{AO}$ 异常下传的特征一致 ${ }^{[11]}$. 另外一点 值得注意的是, 爆发性增温后平流层负的 $\mathrm{AO}$ 信号在 向下传播的过程中并不是一直衰减的, 在对流层低 层还会有一个增强的过程, 这可能与对流层内部动 力过程有关, 值得进一步研究.

从上面的分析可以认为, 较强的行星波上传导 致平流层环流的异常并形成平流层 $\mathrm{AO}$ 负异常, 平流 层 $\mathrm{AO}$ 负异常的下传是这两次负 $\mathrm{AO}$ 过程的重要原因. 在第一个负 $\mathrm{AO}$ 过程中, 平流层环流异常并不强, 但 是平流层高纬的正位势高度异常仍可以向下发展并 影响到对流层, 形成了第一个负 $\mathrm{AO}$ 过程的第一个阶 段; 其第二个阶段是由于对流层低层持续有较强的 正温度异常, 使得从对流层到平流层低层维持了一 个正的位势高度异常并与中纬度的负位势高度异常 构成了负的 $\mathrm{AO}$ 型. 由于这两个阶段的接连发生和共 同作用使得对流层低层经历了一个较强的负 $\mathrm{AO}$ 过 程. 第二个负 $\mathrm{AO}$ 过程主要是由于行星波上传导致了 平流层强爆发性增温的发生, 进而使得平流层产生 了强负 $\mathrm{AO}$ 异常及下传. 通过这两个过程的分析我们 发现, 行星波上传并不一定都会造成爆发性增温的 发生; 也并不只有强平流层异常才能对对流层产生 影响, 平流层弱的极涡异常也可能造成异常信号的 下传并对对流层产生影响.

2009 年 12 月和 2010 年 2 月的两次负 AO 的过 程表明较强的负 AO 异常的形成原因具有一定的复 杂性, 其可能由行星波造成的平流层异常环流下传 造成, 也有可能是对流层环流自身的变化所起的作

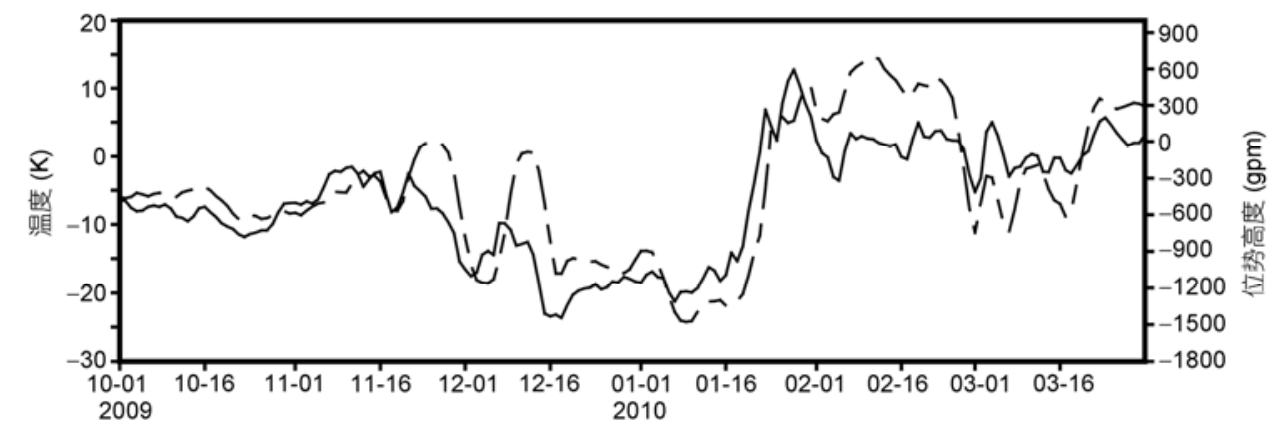

图 92009 年 10 月到 2010 年 3 月 $20 \mathrm{hPa} 90^{\circ} \mathrm{N}$ 与 $60^{\circ} \mathrm{N}$ 上纬向平均温度(虚线)、位势高度(实线)差值的演变 
用. 这里我们定义当北极涛动指数为负值超过 30 天, 同时在此期间北极涛动指数最小值低于 -4 时为一次 负 $\mathrm{AO}$ 事件. 从 1948 年至今挑选出 10 年共 11 次具 有较长持续性的显著负 $\mathrm{AO}$ 事件, 这 11 次负 $\mathrm{AO}$ 事 件的时间分别为: 1951 年 1 月、 1955 年 2 月、1959 年 1 月、1 1966 年 2 月、 1969 年 1 月、 1969 年 2 月、 1977 年 2 月、 1979 年 2 月、1996 年 1 月、1998 年 2 月和 2001 年 2 月. 图 10 是这 11 次负 $\mathrm{AO}$ 事件过程 所对应的(平流层到对流层的) $\mathrm{AO}$ 指数随时间的变化 及北极涛动指数的时间序列. 通过分析我们发现, 在 这 11 次负 $\mathrm{AO}$ 事件中只有 1977 年 2 月和 1998 年 2 月对应平流层强爆发性增温事件, 除了这两次强爆 发性增温事件中有负 $\mathrm{AO}$ 信号从平流层向对流层传 播外, 1969 年 1 月、1979年 2 月和 2001 年 2 月也有 负 $\mathrm{AO}$ 信号从平流层向对流层传播. 这三个过程中平 流层高纬度地区都有正位势高度异常向下发展, 虽 然平流层极浴异常的强度没有达到爆发性增温的水 平, 但是异常信号仍然可以向下传播(图 10). 从 $\mathrm{AO}$ 指数随高度的变化可以看到负 $\mathrm{AO}$ 信号由平流层向 对流层传播的过程, 并且负 $\mathrm{AO}$ 在传播到对流层低层 后都有所增强. 上述 5 个过程之外的各个负 $\mathrm{AO}$ 过程 中, 都出现有对流层 $\mathrm{AO}$ 信号与平流层 $\mathrm{AO}$ 信号反相 的特征, 并且负 $\mathrm{AO}$ 的最大值中心在对流层低层, 可 以认为在这 5 个过程中对流层内部的作用对负 $\mathrm{AO}$ 的 形成和维持起到主要作用. 因此从这 11 次负 $\mathrm{AO}$ 事 件的分析我们不难看出, 负 $\mathrm{AO}$ 事件有可能由平流层 异常信号下传造成, 也有可能由对流层低层内部的 动力过程产生.

\section{$42009 / 2010$ 年冬季 AO 异常的影响}

前面我们已经指出, 2009/2010 年冬季中国东北 大部及内蒙古东部、新疆北部气温较常年偏低 $1 \sim 2^{\circ} \mathrm{C}$, 局部偏低 $2 \sim 4{ }^{\circ} \mathrm{C}$; 东北大部、西北西部、东南沿海大 部以及内蒙古西部和东北部等地的降水较常年偏多, 东北北部、新疆北部、甘肃西北部及内蒙古西部等地 甚至偏多 1 倍以上. 事实上在 2009/2010 年冬季, 整 个北半球都出现了显著的气候异常. 欧亚大陆中高 纬度大范围地区、北美洲中南部等地的气温也较常年 同期偏低 $1 \sim 3^{\circ} \mathrm{C}$, 其中, 俄罗斯中北部、欧洲东北部 偏低 $3 \sim 8^{\circ} \mathrm{C}$. 而北美洲北部、亚洲南部等地的气温较 常年同期偏高 $1 \sim 2^{\circ} \mathrm{C}$, 其中北美洲东北部和西北部等 局部地区气温偏高达 $4^{\circ} \mathrm{C}$ 以上. 已有研究表明作为北
半球年际尺度最强模态的 $\mathrm{AO}$, 其异常不能不对北半 球的气温、降水等造成重要的影响, 因此 2009/2010 年冬季北半球大范围的气候异常和前面讨论的 $\mathrm{AO}$ 强负异常之间必然存在一定的联系, 下面就将分析 研究这次强的 AO 负异常对 2009/2010 年冬季天气气 候的影响.

在全球尺度上, $\mathrm{AO}$ 负(正)位相对应着纬向平均 的中纬度急流向赤道(极地)方向偏移，极浴范围扩大 (缩小), 极浴强度减弱(增强). 在大尺度环流特征上, $\mathrm{AO}$ 负异常表现为中纬度出现明显的大槽大脊, 即经 向型环流明显, 加剧了高纬地区和中低纬地区冷暖 空气的交换; 而 AO 正异常时中纬度地区无明显的槽 脊, 流场较为平直, 即纬向型环流显著, 高纬度的冷 空气被禁锢在极区, 冷暖空气的交换较弱. 为了表明 2009/2010 年冬季 AO 负异常对全球大气环流产生影 响, 我们给出了 2009/2010 年冬季平均的北半球 300 $\mathrm{hPa}$ 经向风异常(图 11(b)). 可以看到在整个北半球的 中高纬度 $\left(40^{\circ} \sim 70^{\circ} \mathrm{N}\right)$ 地区, 经向风有明显的异常分布, 这表明在 2009/2010 年冬季, 相比气候态而言, 中纬 度的环流出现了更为显著的槽脊系统. 伴随着加强 的槽脊系统, 南北的冷暖空气交换加剧, 这使得极区 出现较强的温度正异常, 而整个欧亚大陆的中高纬 地区出现负的温度负异常(图 11(a)). 除了 AO 异常本 身就是行星尺度大气环流异常外, AO 异常还可能造 成大气低频振荡的异常, 从而对天气气候产生影响. 图 12 给出了 2009 年 12 月至 2010 年 2 月逐日 AO 指 数与同期低频 $(20 \sim 70 \mathrm{~d})$ 振荡动能的相关系数分布. 可以看到 $\mathrm{AO}$ 与冬季低频动能有很好的相关性, 部分 地区相关系数超过了 0.8 . 低频振荡作为天气尺度系 统的背景, 可以通过不同尺度环流系统的相互作用 对天气气候产生直接影响. 因而 $\mathrm{AO}$ 异常通过对大气 低频振荡的影响也就必然会对天气气候产生重要作 用. 值得一提的是, $\mathrm{AO}$ 与低频振荡的相关要明显比 与天气尺度(3 8 d) 系统得相关大的多, 表明 AO 异常 对低频系统的影响是更为重要的, 这主要是由 $\mathrm{AO}$ 及 其变化的时空尺度所决定的.

和大气环流和温度异常相对应, 北半球的降水 也出现了大范围异常. 我们引用了中国气象局国家 气候中心绘制的 2009/2010 年冬季(12 2 月)全球陆地 区域降水距平(\%)的分布(图 13). 可以看到北半球的 异常最为明显, 在亚洲中纬度地区(包括我国东北和 

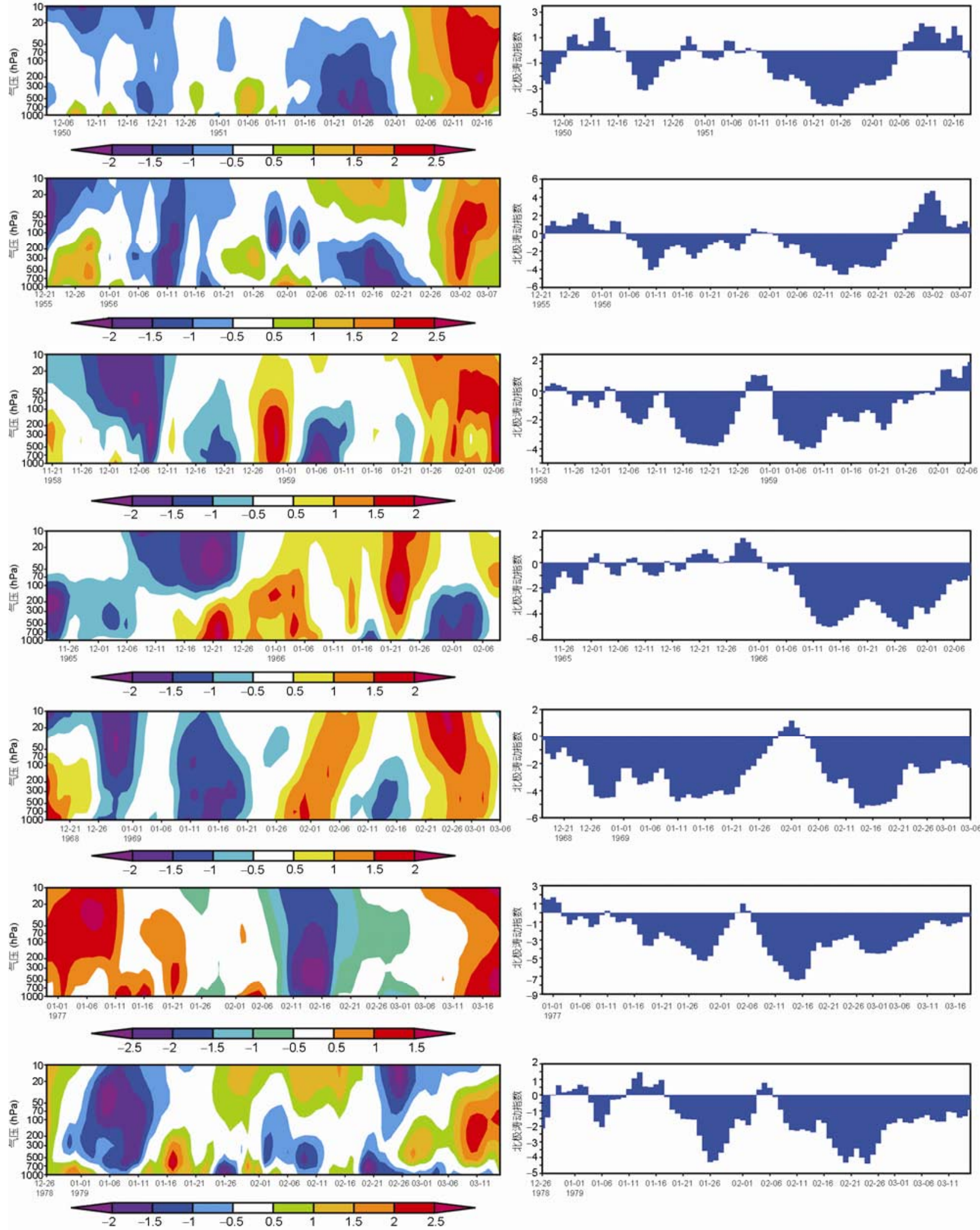

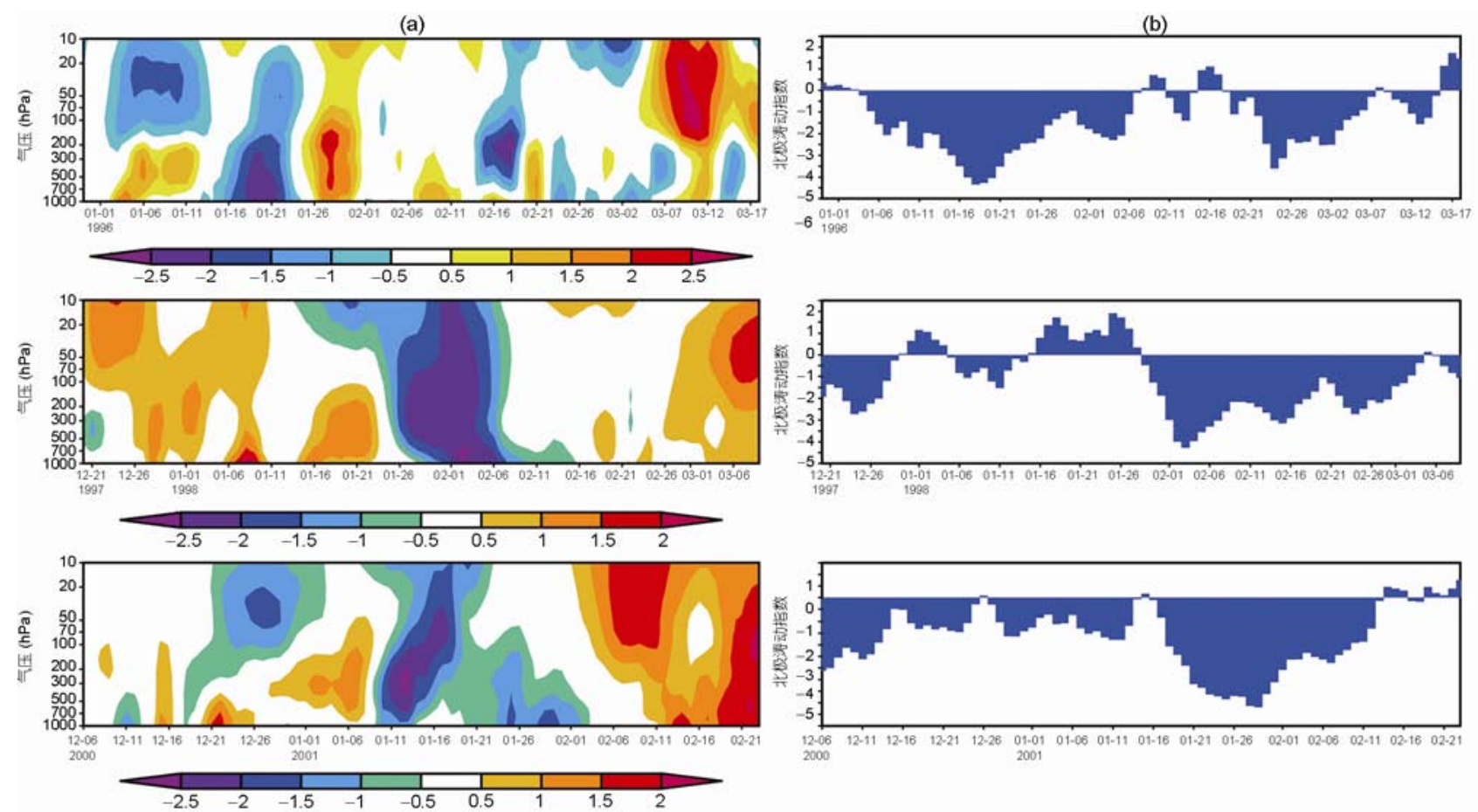

图 1011 次负 $\mathrm{AO}$ 事件过程所对应的(平流层到对流层)AO 指数随时间的变化(a)及北极涛动指数的时间序列(b)
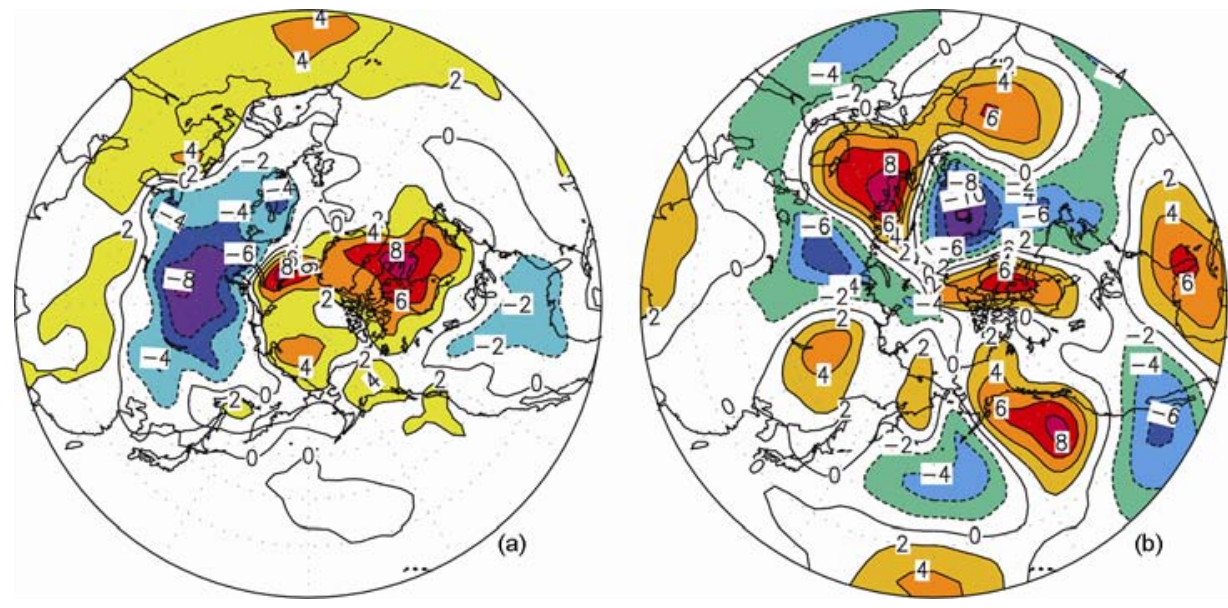

图 112009 年 12 月至 2010 年 2 月平均的北半球 $1000 \mathrm{hPa}$ 温度异常 $(\mathrm{a})$ 和 $300 \mathrm{hPa}$ 经向风异常(b) 温度单位为 $\mathrm{K}$, 经向风单位为 $\mathrm{m} \mathrm{s}^{-1}$

西北)、北美洲中南部, 以及欧洲中部和非洲近赤道地 区有极强的正距平(最大异常达到 2 4 倍); 而南亚地 区(包括我国西南)、非洲北部、俄罗斯中部及北美洲 西北部等地为显著的负距平, 其降水较常年同期偏 少 3 8 成, 局部地区甚至冬季无降水. 图 13 中也可清 楚表明我国云南及附近地区有严重干旱，有关 $2009 / 2010$ 年冬季云南干旱的具体成因(包括 AO 异常
的影响)我们正在另外一个研究中给予系统分析, 这 里将不去讨论.

图 11 和 13 清楚地表明了 2009/2010年冬季北半 球天气气候异常的严重性, 不仅异常的强度大, 而且 异常的范围广. 虽然这些天气气候异常并不全都是 $\mathrm{AO}$ 异常所造成的, 但是北极涛动(AO)异常对北半球 天气气候的重大影响依然需要引起我们的关注. 


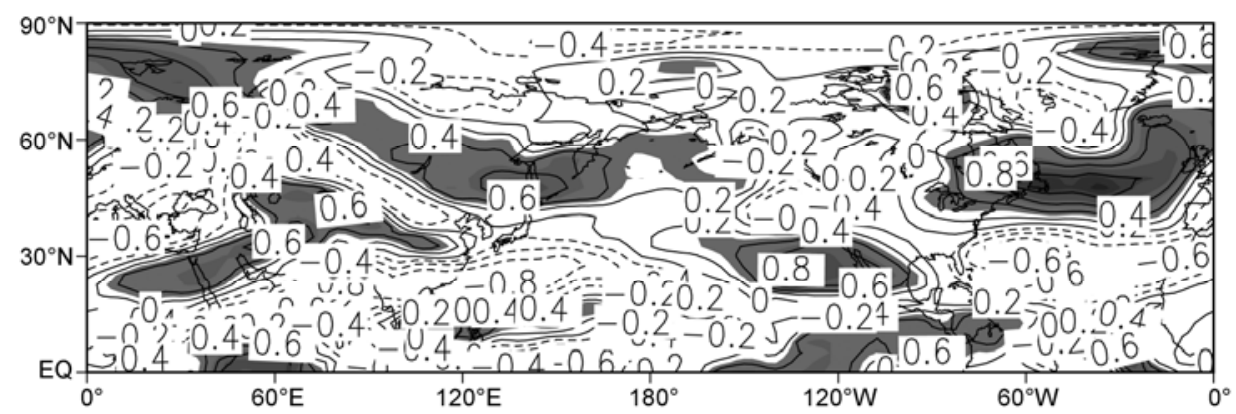

图 122009 年 12 月至 2010 年 2 月逐日 $A O$ 指数与同期低频 $(20 \sim 70$ d)动能的相关系数分布 阴影区域表示通过 0.05 的信度检验

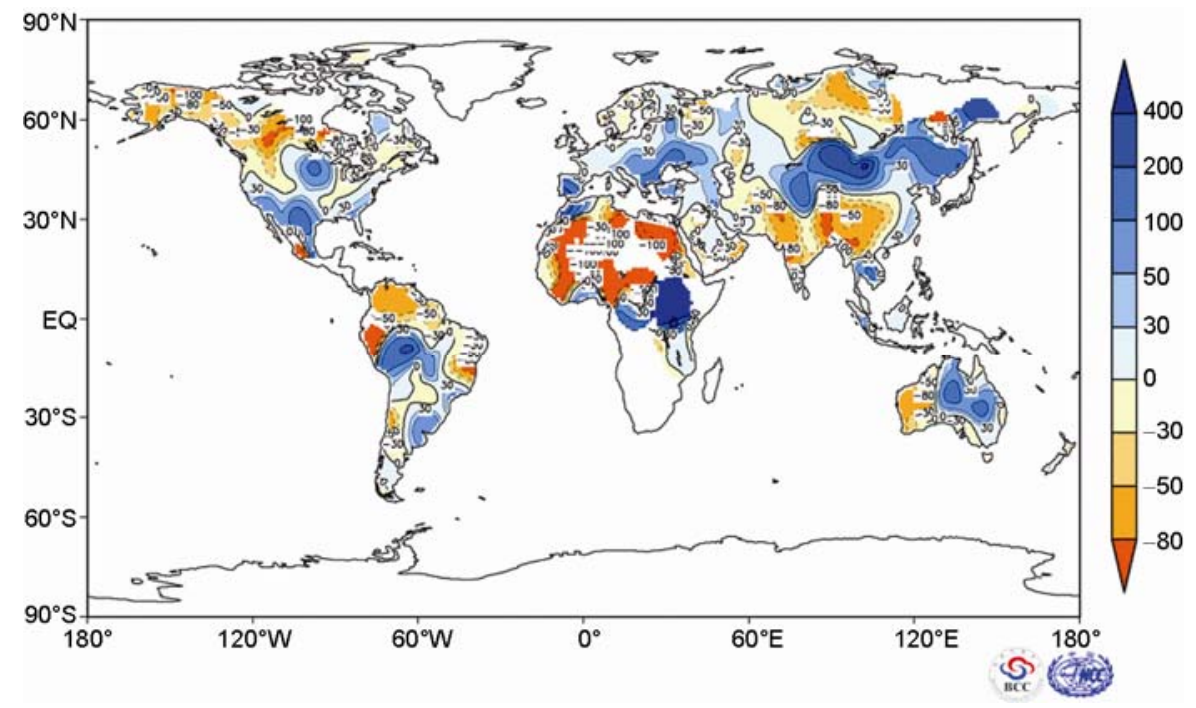

图 $132009 / 2010$ 年冬季(12 2 月)全球降水距平百分率 $(\%)$ 的分布 国家气候中心提供

\section{5 结论与讨论}

通过对 AO 指数的分析我们发现 2009/2010 年冬 季经历了两个 $\mathrm{AO}$ 负异常过程, 较强的行星波上传并 导致平流层环流的异常是这两次 $\mathrm{AO}$ 负异常过程的 重要原因. 其中 2009 年 12 月的 $\mathrm{AO}$ 负异常过程又可 以分为两个阶段: 第一个阶段主要是由于前期行星 波上传的增强导致平流层极浴减弱, 平流层环流异 常向下发展造成了对流层的 $\mathrm{AO}$ 负异常; 第二个阶段 是由于对流层低层高纬度地区的正温度异常使得第 一个阶段在对流层高纬度地区正位势高度异常的维 持, 进而使得 $\mathrm{AO}$ 负异常维持较长时间. 正是上述这 两个阶段的接连发生和共同作用, 造成对流层低层 环流经历了一个较强的 AO 负异常过程. 通过对 500
$\mathrm{hPa}$ 位势高度场的分析, 我们认为北大西洋阻塞高压 的持续维持可能是第二个阶段对流层高纬度的正温 度异常产生的原因. 2010 年 2 月的 AO 负异常过程则 是由平流层爆发性增温所造成的平流层异常环流下 传所造成的. 通过对这两个过程的分析我们发现, 行 星波上传并不一定都会造成爆发性增温的发生，但 弱的平流层极浴异常也可能对对流层产生影响.

以往的研究指出平流层强的极浴异常信号能够 下传并影响对流层, 而在本文的研究中我们发现, 平 流层较弱的环流异常也有可能向下发展并影响到对 流层，但其机制还有待进一步的深入研究. 在我们所 挑选的过去 11 个 $\mathrm{AO}$ 负异常事件的统计中, 有 2 次 是由于平流层爆发性增温造成的, 3 次是由于平流层 弱异常下传造成, 6 次来源于对流层自身的变化. 而 
2009 年 12 月的 AO 负异常过程是由平流层弱异常下 传和对流层内部自身的变化共同作用造成的，因此 $\mathrm{AO}$ 负异常事件的原因是相对比较复杂的, 对于此类 $\mathrm{AO}$ 负异常件的预测还需要进行多方面的考虑.

2009/2010 年冬季持续较强的 AO 负异常造成了 整个北半球的中高纬度 $\left(40^{\circ} \sim 70^{\circ} \mathrm{N}\right)$ 地区经向风异常, 使得北半球中纬度的环流出现了更为明显的异常槽 脊系统. 伴随着加强的槽脊系统, 南北的冷暖空气交 换加剧, 极区出现较强的温度正异常, 而整个欧亚大
陆的中高纬地区出现明显的负温度异常. 此外, 北美 洲中南部、欧洲南部、亚洲中部和东部等地降水出现 了较强的降水异常. 冬季的 $\mathrm{AO}$ 强异常对北半球的大 气环流和天气气候有着极为严重的影响, 需要在研 究和实际预报预测中给予重视.

本文从大气环流的角度研究了 2009/2010 年 AO 的异常特征及其发生原因, 也讨论了这次强 $\mathrm{AO}$ 负异 常对北半球天气气候异常的可能影响. 相应的数值 模拟试验将是下面要进一步开展的研究工作. 意见.

\section{参考文献}

1 Thompson D W J, Wallace J M. The Arctic oscillation signature in the wintertime geopotential height and temperature fields. Geophys Res Lett, 1998, 25: 1297-1300

2 Wallace J M. North Atlantic oscillation/annular mode: Two paradigms-one phenomenon. Q J R Meteorol Soc, 2000, 126: 791-805

3 Li J P, Wang J X L. A modified zonal index and its physical sense. Geophys Res Lett, 2003, 30: 1632, doi: 10.1029/2003GL017441

4 李建平. 北极涛动的物理意义及其与东亚大气环流的关系. 见: 俞永强, 陈文, 等. 海-气相互作用对我国气候变化的影响. 北京: 气 象出版社, 2005. 169-176

5 Thompson D W J, Wallace J M. Annular modes in the extratropical circulation. Part I: Month-to-month variability. J Clim, 2000, 13: 1000-1016

6 Baldwin M P, Dunkerton T J. Propagation of the Arctic oscillation from the stratosphere to the troposphere. J Geophys Res, 1999, 104: $937-$ 946

7 Baldwin M P, Stephenson D B, Thompson D W J, et al. Stratospheric memory and skill of extended-range weather forecasts. Science, 2003, 301: 636-639

8 Thompson D W J, Baldwin M P, Wallace J M. Stratospheric connection to northern hemisphere wintertime weather: Implications for prediction. J Clim, 2002, 15: 1421-1428

9 Black R X. Stratospheric forcing of surface climate in the Arctic oscillation. J Clim, 2002, 15: 268-277

10 Baldwin M P, Thompson D W J, Shuckburgh E F, et al. Weather from the stratosphere? Science, 2003, 301: 317-318

11 李琳, 李崇银, 谭言科, 等. 平流层爆发性增温对中国天气气候的影响及其在 ENSO 影响中的作用. 地球物理学报, 2010, 53: $1529-1542$

12 Wang L, Chen W. Downward Arctic oscillation signal associated with moderate weak stratospheric polar vortex and the cold December 2009. Geophys Res Lett, 2010, 37: L09707, doi: 10.1029/2010GL042659

13 Satio K, Cohen J. The potential role of snow cover in forcing interannual variability of the major Northern Hemisphere mode. Geophys Res Lett, 2003, 30: 1302, doi: 10.1029/2002GL016341

14 Cohen J, Barlow M, Kushner P J, et al. Stratosphere-troposphere coupling and links with Eurasian land-surface variability. J Clim, 2007, 20: 5335-5343

15 Gong D Y, Wang S W, Zhu J H. East Asian winter monsoon and Arctic oscillation. Geophys Res Lett, 2001, 28: 2073-2076

16 龚道溢，朱锦红，王绍武. 长江流域夏季降水与前期北极涛动的显著相关. 科学通报, 2002, 47: 546-549

17 陈文, 康丽华. 北极涛动与东亚冬季气候在年际尺度上的联系：准定常行星波的作用. 大气科学, 2006, 30: 863-870

18 Ren R C, Cai M. Meridional and vertical out-of-phase relationships of temperature anomalies associated with the Northern annular mode variability. Geophys Res Lett, 2007, 34: L07704, doi: 10.1029/2006GL028729

19 杨辉，李崇银. 冬季北极涛动的影响分析. 气候与环境研究, 2008, 13: 395-404

20 李崇银, 顾薇, 潘静. 梅雨与北极涛动及平流层环流异常的关联. 地球物理学报, 2008, 51: 1632-1641

21 Chen W, Takahashi M, Graf Hans-F. Interannual variation of stationary planetary wave activity in the northern winter troposphere and 
stratosphere and their relation to NAM and SST. J Geophys Res, 2003, 108(D24): 4797, doi: 10. 1029/2003JD003834

22 Baldwin M P, Thompson D W J. A critical comparison of stratosphere-troposphere coupling indices. Quart J Roy Met Soc, 2009, doi: 10.1002/qj.479

23 Charney J G, Drazin P G. Propagation of planetary-scale disturbances from the lower into the upper atmosphere. J Geophys Res, 1961, 66: 83-109

24 Andrews D G, Holton J R, Leovy C B. Middle Atmosphere Dynamics. Salt Lake City: Academic Press, 1987. 1-489

25 Matsuno T. A dynamical model of the stratospheric sudden warming. J Atmos Sci, 1971, 28: 1479-1494 